\title{
Your kids, our future: Diverging perspectives of parents and society on the child body, obesity and responsibility
}

\section{Stephanie Kowal}

\author{
University of Alberta
}

Current trends suggest that global childhood obesity rates will continue rising. ${ }^{1}$ These rates concern society because of their magnitude and economic impacts, ${ }^{1}$ which cost Canada up to $\$ 4.3$ billion yearly. ${ }^{2}$ Childhood obesity in Canada has almost tripled since 1985, putting over $25 \%$ of its children into unhealthy weight categories. ${ }^{3}$ Obesity interventions and prevention target children because they are a captive audience, learning habits that can promote healthy living and reduce the disease risks associated with chronic obesity. ${ }^{1}$

Using Uprichard's concept of 'being' and 'becoming', ${ }^{4}$ I argue that parental and societal understanding of the child body differ, impacting the effectiveness of foodoriented childhood obesity interventions. First, this article explains that familial bonds cause parents to focus on their individual children in the present, or the 'being' child. Second, it discusses society's understanding of obesity as a problem requiring future-oriented and impersonal interventions, viewing children as the future, or the 'becoming' child. Because parents are responsible for governing their children's diets and routinizing healthy eating habits, ${ }^{5}$ obesity interventions must recognize parental understanding of 'being' children to optimize nutrition-based obesity interventions.

Children's bodies are dichotomous entities, embodying present and future, the threatening and threatened. 'Being' children are social actors living in the present and reacting to their current environments. 'Becoming' children are future adults, or 'adults in the making' lacking the skills and features of the adults they will become. ${ }^{6}$ Children's bodies are threatening because, without regulation, they lack the self-control or common sense, to practice effective self-governance required to make healthy food choices. ${ }^{7}$ Children risk developing poor eating habits if left unregulated, leaving their bodies vulnerable to the development of chronic obesity and associated illnesses.
Thus, it is precisely their vulnerability that renders them threatening. Without learning the healthy eating habits required to prevent obesity, children pose a threat of perpetuating unhealthy lifestyles through their own children in the future.

Childhood obesity's prominent societal discourses argue that parents are responsible for "curb[ing] and control[ing] their children's food choices and appetites". ${ }^{5}$ This responsibility can conflict with parental instinct, fiscal ability, and/or legal requirements to provide nourishment and ensure that children gain weight with age. ${ }^{8}$ Whether obesity results from wealth and over-provision, or from poverty and lack of access to healthy food, ${ }^{3}$ parental feeding patterns are driven by the need to provide sustenance to their 'being' child.

Additionally, parental feeding choices are influenced by a fear of creating food and body-image diseases such as anorexia nervosa, bulimia, or secretive eating resulting from restrictive childhood relationships with food. ${ }^{9}$ Parental perspectives on healthy food can be tenuous because fixating on 'correct' food choices can spark control-related eating disorders. ${ }^{9}$ Some choose to restrict dietary choices overtly to promote healthy body weight. Others act neutral towards food choices in order to avoid creating eating disorders which can potentially harm the child. ${ }^{9}$ The legal and instinctive requirements of parenting may benefit the 'becoming' child but parents' foremost concern is protecting their 'being' children.

Obesity is unhealthy for the 'being' child, but the 'becoming' child is more threatening in the society and government's view. Given rising obesity costs, ${ }^{2}$ children are perceived as a potentially problematic generation of obese adults. However, we also view children's bodies as sites where we can intervene with healthy food programs preventing future medical and socio-economic suffering. Government 
interventions such as healthy lunch program subsidies or legislation to ban school vending machines regulate child health behaviour, making their generation less threatening to the collective future's success. Viewing obesity as threatening to the future of children and society situates the body as an effect of disease, void of all individual characteristics apart from its relation to disease..$^{10}$ Obese bodies are thus, physical markers symbolizing future generations potentially dealing with chronic diseases associated with obesity.

In practice, public health treats bodies in this impersonal way because of its wide-reaching disease prevention and monitoring responsibilities. Government programs aiming to restrict children's diets are focused on the well-being of the collective future, what children will be (parents, workforce) instead of what they are. ${ }^{4}$ Close familial connections with their 'being' children hinder parental conceptualization of their children as part of this impersonal collective future. These familial bonds cause parents to prioritize the happiness of the 'being' child.

The notion of 'being' and 'becoming' in relation to childhood obesity highlights how parenting decisions become difficult in the face of societal requests to restrict childhood food intake. This argument is limited to food restriction intervention and does not aim to deemphasize the role of larger structural barriers to child health (poverty, access to healthy food, etc.). Rather, it shows that different psychosocial perspectives of children's bodies impact obesity interventions. By exploring ways to develop interventions aligning with parental priorities of their 'being' children rather than emphasizing obesity reduction for a 'becoming' generation, we will enrich strategies to address the increasing rates ${ }^{1}$ of childhood obesity.

\section{Acknowledgments}

I would like to thank Cassandra Richie, Corey Krahn, and Ken Fraser for their valuable feedback during the preparation of this article.

\section{References}

1. Wang Y,Lobstein T. Worldwide Trends in Childhood Overweight and Obesity. International Journal of Pediatric Obesity.2006; 1: 11-25.

2. Katzmarzyk PT, Janssen I. The economic costs associated with physical inactivity and obesity in Canada: an update. Canadian Journal of Applied Physiology. 2004; 29[1]:90-115.

3. Rosenthal S. The Canadian Type 2 Diabetes Sourcebook 3rd Edition. Mississauga, Ont: John Wiley and Sons; 2009

4. Uprichard E. Children as 'Being and Becomings': Children, Childhood and Temporality. Children and Society. 2008; 22[4]:303-313.

5. Zivkovic T, Warin M, Davies M, Moore V. In the name of the child: The gendered politics of childhood obesity. Journal of Sociology. 2010; 46[4]: 375-392.

6. Brannen J, O'Brien M. Childhood and the sociological gaze: paradigms and paradoxes. Sociology. 1995; 29:729-737

7. Kristeva J. Powers of horror: an essay on abjection. New York: Columbia University Press; 1982.

8. Kruk E. Child custody, access and parental responsibility: The search for a just equitable standard. Father Involvement Research Alliance, 2008.

9. Bryant-Waugh R. Feeding and Eating Disorders in Infancy and Childhood. In: Skuse D, Bruce H, Dowdney L, Mrazek D, editors. Child Psychology and Psychiatry: Frameworks for Practices. 2nd Ed. Chichester: John Wiley \& Sons; 2011. p. 128-222

10. Nettleton S. Protecting a vulnerable margin: Towards an analysis of how the mouth came to be separated from the body. Sociology of Health and IIIness. 1985;10:156-169.

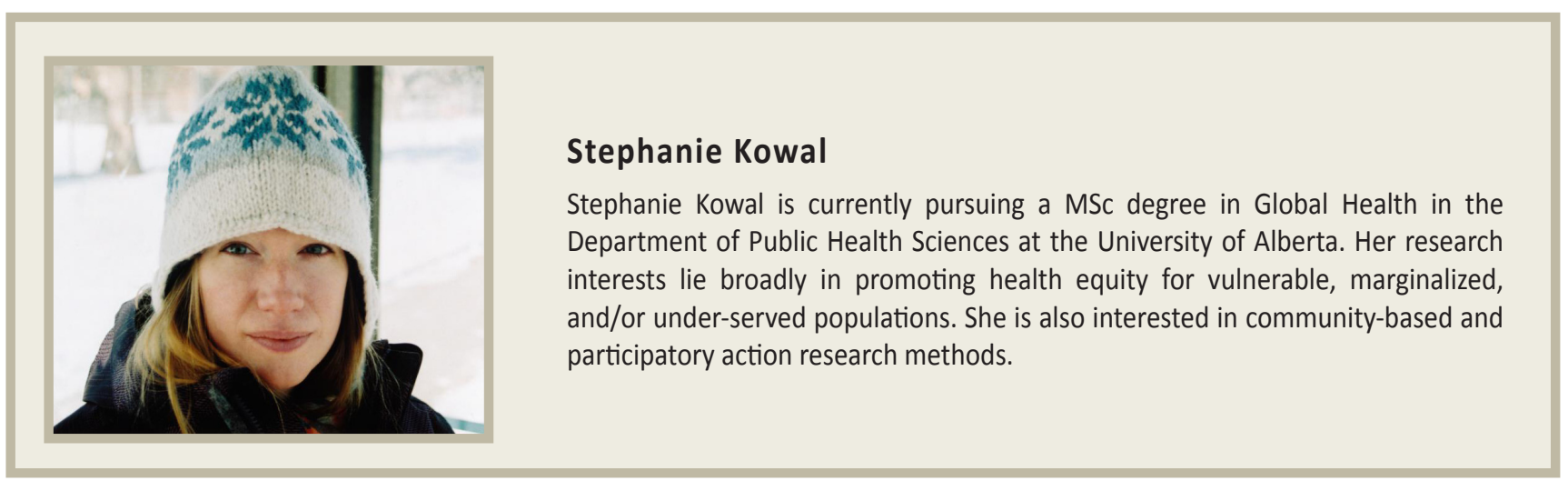

